\title{
Introvert vs. Extrovert: Emotional Differences and Responses towards a Provocative Visual Stimuli in Social Media
}

Siti Ramizah Khairunnisa Mohd Radzi, Jusang Bolong

To Link this Article: http://dx.doi.org/10.6007/IJARBSS/v11-i12/10989

DOI:10.6007/IJARBSS/v11-i12/10989

Received: 17 October 2021, Revised: 21 November 2021, Accepted: 01 December 2021

Published Online: 19 December 2021

In-Text Citation: (Radzi \& Bolong, 2021)

To Cite this Article: Radzi, S. R. K. M., \& Bolong, J. (2021). Introvert vs. Extrovert: Emotional Differences and Responses towards a Provocative Visual Stimuli in Social Media. International Journal of Academic Research in Business and Social Sciences, 11(12), 1310-1323.

Copyright: (c) 2021 The Author(s)

Published by Human Resource Management Academic Research Society (www.hrmars.com)

This article is published under the Creative Commons Attribution (CC BY 4.0) license. Anyone may reproduce, distribute, translate and create derivative works of this article (for both commercial and non0-commercial purposes), subject to full attribution to the original publication and authors. The full terms of this license may be seen at: http://creativecommons.org/licences/by/4.0/legalcode

Vol. 11, No. 12, 2021, Pg. 1310 - 1323

Full Terms \& Conditions of access and use can be found at http://hrmars.com/index.php/pages/detail/publication-ethics 


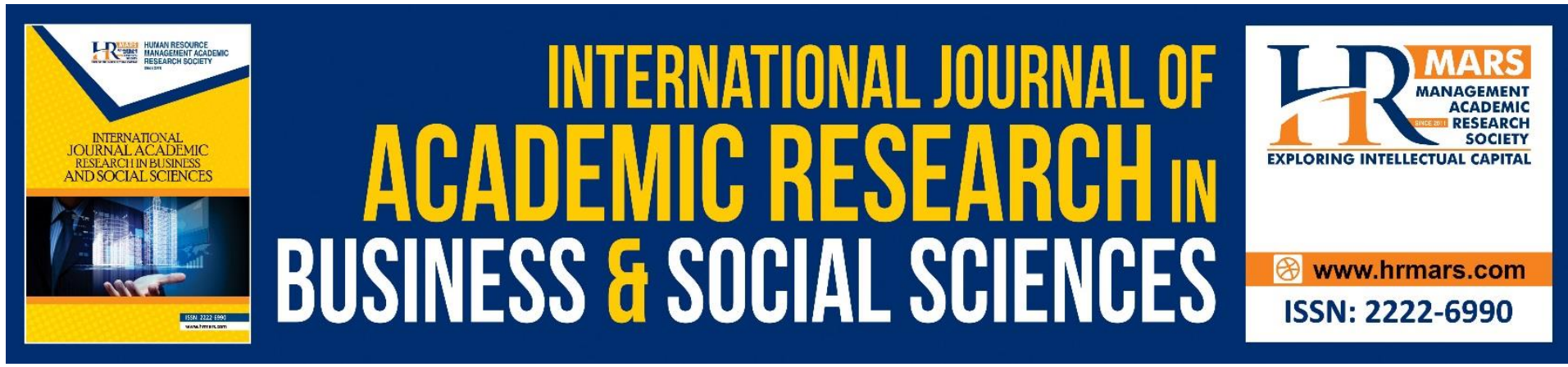

\title{
Introvert vs. Extrovert: Emotional Differences and Responses towards a Provocative Visual Stimuli in Social Media
}

\author{
Siti Ramizah Khairunnisa Mohd Radzi, Jusang Bolong \\ Communication Department, Faculty of Modern Languages and Communication, Universiti \\ Putra Malaysia, Serdang, Selangor, Malaysia. \\ Email: sramizahk@gmail.com, jusang@upm.edu.my
}

\begin{abstract}
This study aims to determine the emotional differences through a visual stimuli watched in social media towards two personalities; namely Introvert and Extrovert. Activities in social media are associated with personalities as each user can hide their identities from the knowledge of other users. Not only that, each personality tends to deal with different emotional states (stability-neuroticism) when interacting or socializing with others in social media. By using an online experimental approach, a total of 60 subjects ( 30 Introverts and 30 Extroverts) aged 20-29 were selected on Facebook and they were provoked with a visual uploaded in the group. The emotional differences for each personality were analysed using the Wilcoxon Matched-Pair Signed Rank Test. Results suggested that the provocative visual stimuli affected the Extroverts' emotional stability $(Z=-2.099, p=0.036)$ more than the Introverts $(Z=-1.170, p=0.077)$, the Extroverts are highly responsive while the Introverts are more sarcastic even in a stable emotional states. Therefore, it can be said that a visual exposure affects the emotional states and the responses towards the content of the visual also plays a role in influencing both personalities' emotions.
\end{abstract}

Keywords: Personality, Social Media, Provocative Visual Stimuli, Emotional States, Online Experiment

\section{Introduction}

Social media has become a protected channel that allows each personality to act differently in a face-to-face (FTF) environment (Tosun \& Lajunen, 2010; Ljepava et al., 2013). A user can hide their identities by using a pseudonym because social media has been used as a terrain to say harsh and rude words (Laflen \& Fiorenza, 2012; Qiu et al., 2012), therefore, it leads to emotional distress especially when the users confront provocative contents (Carlo et al., 2012). Moreover, some of the users upload statuses, sharing pictures or videos as an act of personal views; however, the content may violate manners and cultures, defame or provoke others.

A user fails to interpret the exact meaning of a message, thus creates an easy-to-understand interpretation (Parkinson, 2008) as it will provide a wider meaning especially in social media 
(Laflen \& Fiorenza, 2012). Moreover, the pressure or stimulation from content disseminated in social media will trigger individual emotions too (Codispoti et al., 2008). Interestingly, the changes in emotions may vary by personalities. For example, Psychotic individuals act differently when they socialize either in FTF or social media (Tosun \& Lajunen, 2010) because they assume that social media is a substitute for FTF interactions in expressing one's true self.

Message dissemination in social media is divided into three; text, visual, or combination of both. Usually, the use of a visual will influence the user's impression as compared to texts or interactions (Heide et al., 2012). It will encourage the involvement on both sides to exchange comments, thus tighten the relationship between users. Moreover, the discrepancies in results involving the way each individual interacts and socialises require further discussions especially on the emotional perspectives as emotions of each online personality cannot be physically viewed in social media.

There are numerous studies that provide various insights on the Extrovert and Introvert characters in FTF and in social media. Some of the researchers found that Extrovert and Introvert characters have no difference either in FTF or in social media (Tosun \& Lajunen, 2010; Wilson et al., 2010) and some said otherwise (Mitchell et al., Shoger 2011; Orchard et al., 2014). Therefore, it triggers a question on how each personality's emotions can be affected by the sharing of visual materials in social media.

\section{Social Media}

Social media acts as a powerful channel because users can bypass or avoid the feedbacks, exploit or postpone an interaction for various reasons (Parkinson 2008). Futhermore, they can choose a topic, a people to converse with, respond to, and leave the conversation at any time (Okdie et al., 2011). Individuals' reactions in social media do not only involve selfpresentation and impression management process, but a message that cannot be entirely explained in FTF will be re-arranged and transformed into a meaningful message re-shared in their own way (Walther 1996; 2007).

Social media is a relevant example in explaining the use of Hyperpersonal Models. The models explained that the effects on the use of social media are divided into four elements; sender, receiver, channel, and feedback (Walter, 1996). Therefore, the impact of social media can be detected through individuals interact, socialize, and hide the emotions from the knowledge of other users. Furthermore, every user will have the potential to be exposed to any online material that will influence the users' emotions (Alhabash et al., 2015) and the exposure will influence each user's emotions to become stable or unstable.

Social media features contradict from FTF environments, as well as individual personality. Personality is a combination of emotions, attitudes, behaviors, and responses. Each behavior, thought and emotion varies from their neurobiological systems (Stemmler \& Wacker 2010). The interaction style of each personality is an interesting topic to explore as each character tends to utilise the channel as an extension or substitution (Tosun \& Lajunen, 2010), do online activities (Moore \& McElroy 2012; Wang et al. 2012), disclose personal information, (Hollenbaugh \& Ferris, 2014) or express linguistic signals (Qiu et al., 2012). 


\section{Personality}

In general, the difference in personality can be seen in two criteria; neurobiology and social interactions (Eysenck \& Eysenck, 1975; Srivastava et al., 2008). Firstly, Eysenck and Eysenck (1975) mentioned that Extroverts' brain stimulations are lower than Introverts, thus they are more likely to get bored when they are exposed to a noisy environment and vice versa. Secondly, Extroverts will often engage in social interaction and develop more positive emotions while the Introverts are still socializing with others but they often withdraw because of personal factors (Srivastava et al., 2008).

Past studies have presented varying findings on Extrovert personality. According to Wilson et al. (2010), the Extroverts will spend longer time to socialise, expand the conversation started in FTF and prefer to chat using a short and incomplete words because they want to talk quickly with many friends at one time (Qiu et al., 2012). Furthermore, they also like to upload their own selfies in social media compared to photos taken by another person (Kramer et al., 2017). This situation explains that the Extrovert will perform a variety of activities including interact and form relationships with other users in social media.

Interestingly, several studies prove that the Extroverts are not much different from the Introverts. For example, the Extroverts spend lesser time and never disclose personal information in social media (Moore \& McElroy, 2012; Winter et al., 2014). The similarities can be found among the Introverts as they too, would not provide information that had already been given offline due to the discomfort feeling to search for new friends in the online space (Orchard et al., 2014). Although Mitchell et al (2011) says the Introverts spend more time browsing online activities as it will make them happier, it happens because they were comfortable to keep in touch with the same friends known in FTF (Lorenzo-Romero \& Amo, 2012).

A personality dimensions created by Eysenck and Eysenck (1975) namely Eysenck Personality Wheel has stated that personality traits can be explained as in Figure 1 . The dimensions are Extroversion trait (Extrovert-Introvert), the Neuroticism trait (Emotional stability-Emotional instability) and Psychotic-Impulse Control. Moreover, two of the three dimensions have its own temperament domains. The four temperaments are (1) Extroverted - Emotionally Stable (Sanguine), (2) Extroverted - Emotionally Unstable (Choleric), (3) Introverted - Emotionally Stable (Phlegmatic) and (4) Introverted - Emotionally Unstable (Melancholic). 


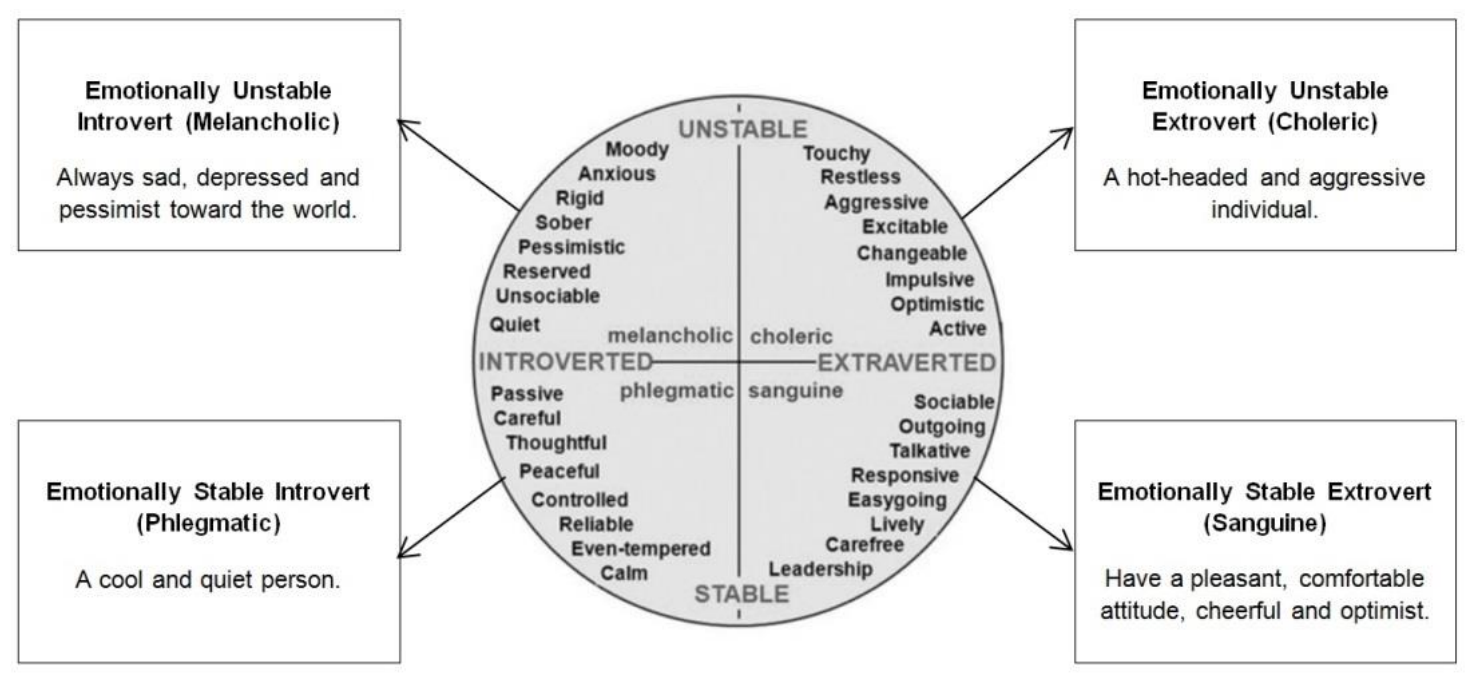

Figure 1: Eysenck Personality Wheel

\section{Emotional Communication}

Emotional communication is defined as an expression or mood sharing between two or more individuals; by using continuous movement through body gesture or facial expression (Derks et al., 2008; Parkinson, 2008). Emotional expression is very difficult to understand (Huang et al., 2008) because the changes in emotions are influenced by the environment, relationships, and social characters (Sparrevohn \& Rapee, 2009; Dezecache et al., 2013; Hammick \& Lee 2014). In a simple term, emotional expression to a partner is a form of emotional commitment (Laflen \& Fiorenza, 2012) therefore, responses are important in influencing individual emotions.

A temporary delays caused by slow Internet speed will also influence individuals' emotions (Powers et al., 2011) because when the delays interfered with conversation accuracy thus leads to disappointment because both users cannot reciprocate at the same time. A research related with emotional changes can be measured psychologically (self-report) and physiologically (electroencephalogram, EEG; electrodermal, EDA). Not only that, a visual content such as pictures, films or videos will affect individuals' responses higher than the use of text or verbal (Rooney et al., 2012; Alhabash et al., 2015; Heide et al., 2012).

Furthermore, a stimulus can be from a controllable source (internal - provided materials) and also uncontrollable source (external - the environment). For example, a visual quality would impede individuals' attentions to maintain the interaction as they felt delayed over time. The delay in cues and responses would weaken the feedback process with the person they are interacting with (Powers et al., 2011). Furthermore, a 3D visual feature with a disgust theme would further affect individuals' emotions (Rooney, Benson \& Hennesy, 2012) thus influence their civic behavior to respond on the content (Alhabash et al., 2015).

The study on emotional changes in social media are related with emotional instability because the individuals want to stay connected with their online friends (Moore \& McElroy, 2012; Qiu et al., 2012), but they will use the social media as a substitute medium for interaction (Tosun \& Lajunen, 2010) and evasion (Orchard et al., 2014). A linguistic signals study by Qiu et al., (2012) has proven that individuals with unstable emotions will use harsh and negative words 
in social media because the instability state has triggered them to use inappropriate language not only in uploaded posts but in the comment sections as well (Kadri et al., 2019).

The emotional presentation style on Facebook is varied according to privacy and audience (Bazarova et al., 2012). They can choose to present their emotions through wall posts (status updates) or in personal messages (inbox). Each section allows users to use the alias; @, and the hashtag; \#, to make a post more focus and private. It is an act of self-presentation to gain attention therefore; they will update their everyday activity as a way to reduce loneliness (Wang et al., 2012). Furthermore, choosing a right location may help the individual to control their emotional states as they will behave appropriately in social media.

\section{Hypothesis}

An early study on the effects of stimuli among personalities showed that the Extroverts were able to adapt with a loud tone (Geen, 1984), engaged with a lower level of brain activity (Gale et al., 2001) thus, it actively sought external stimulation from the environment. Therefore, several hypotheses have been proposed and it is expected that the dissemination of stimuli in social media will affect the changes in the personalities' emotional states.

$\mathrm{H} 1$ : There is a significant difference in emotional changes among Extroverts before and after the exposure to visual stimuli in social media.

$\mathrm{H} 2$ : There is a significant difference in emotional changes among Introverts before and after the exposure to visual stimuli in social media.

\section{Methodology}

\section{Research Design}

This study was conducted in the form of pre- and post-test online experiments with a focus on the effect of provocative visual stimuli on emotional changes towards the personalities; Introverts and Extroverts.

\section{Participants}

A total of 183 samples were selected as the early respondents for this study. Out of 183, only 105 agreed to participate in the research. Although experimental study does not require many samples, there is a tendency for the subject to withdraw during mid-test (Reips, 2002) or did not complete the questionnaires. Furthermore, Sani and Todman (2006) mentioned that 20 respondents were adequate for experimental research. Therefore, 30 respondents from each personality have been selected thus giving an overall total of 60 respondents.

Social media Facebook was chosen as the platform for online study because it has the highest number of active users in Malaysia (Malaysian Communications \& Multimedia Commission, 2021). Moreover, university students generally knew as the most active social media users (Mack et al., 2007). In a nutshell, this study chose 60 university students (30 Introverts and 30 Extroverts) between 20-29 years old who are actively involved in Facebook as the participants for the study. The data collection procedures were carried out in the group.

\section{Measures}

The subject's identities were substituted using code (E1-E30, 11-130) and conducted in two phases: 1) Personality screening and 2) Emotional changes. Both phases were measured using 
the Eysenck Personality Questionnaire-Malay version by Asgari (2002). A total of 19 closedended (Yes / No) questions were related with personalities such as "I can easily get involved in boring parties", "I often do what I like right away" and "I prefer reading books than meeting other people".

Next, a total of 21 questions on a scale 1 to 5 related with current emotions felt at that time (before and after exposure to visual stimuli) such as "my mood always changes", "I feel lonely" and "I think life is too boring". All subjects answered the questionnaire in 3 sections namely (1) personality, (2) emotional state before, and (3) emotional state after. The reliability value for each constructs for Introverts was 0.822 (pre) and 0.782 (post) while the value of 0.907 (pre) and 0.917 (post) was for Extroverts.

\section{Visual Stimuli}

A one-sided emotional visual (e.g: negative only) tends to affect individual's emotions to be more sensitive and difficult to control, thus fails to interpret the content of the visual accurately (Gallo et al., 2009; Rafnsdottir, 2012). Therefore, the visuals used in the study is a combination of several types of emotions (positive and negative) which related to a political campus' speeches of two political parties (government and opposition) in the university. The speeches were intended to stimulate students' emotion to trust the political leader and ignore the interference from the university's administration. Figures 2 and 3 illustrate the sample interface of campus politics visual at two universities in Malaysia.
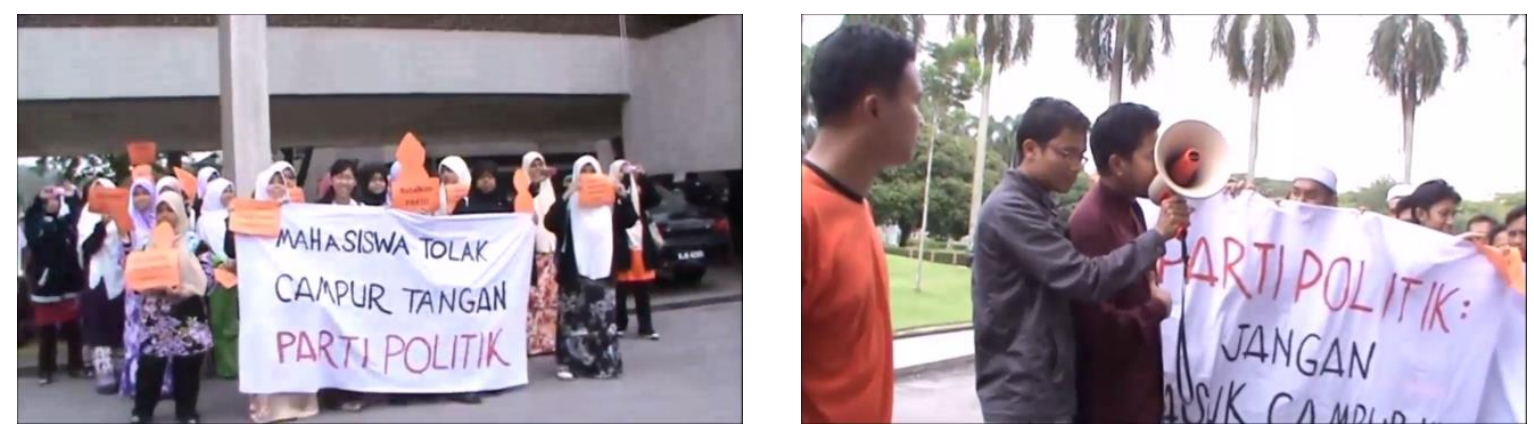

Figure 2: Peaceful Assembly by Pro-Mahasiswa
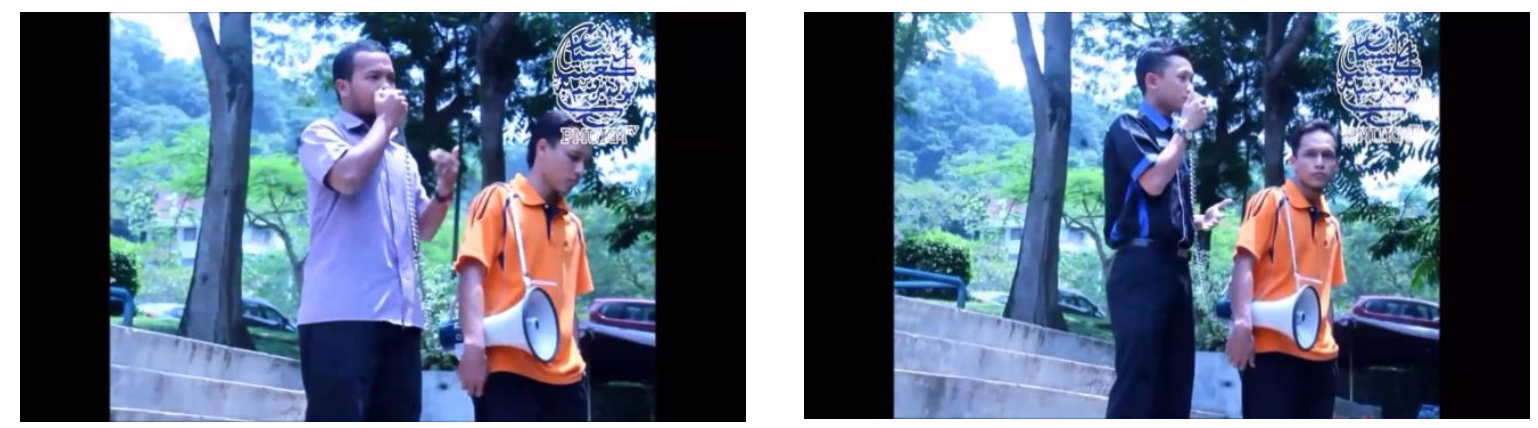

Figure 3: Presidential Picket - The Political Direction

\section{Procedures}

All 105 respondents were added to a Facebook group named Emotion and EPQ. They were asked to answer questions related to personality and emotional state before and after watching the visual. The data were collected in 4 stages: (1) Notice on the experiment schedule (four days), (2) Notice to answer the questionnaires - before (four days), (3) Notice 
to watch visual stimuli (five days) and (4) Notice to answer the questionnaires - after (four days). All questions were given online via google.doc and every phase was locked to avoid multiple data collection.

The synchronicity of each questionnaire has been determined through the personality code set after answering stage 2 . Subjects who failed to cooperate were removed; bringing the total number of final subjects to 60 after the personality analysis was conducted. Not only that, the engagement of watching visual stimuli could also be seen through the "seen by" in the comments section.

\section{Analysis}

All data were analyzed using the non-parametric analysis; Wilcoxon Matched-Pair Signed Rank Test. This method of analysis was suitable to compare the median between two groups (pre and post). Moreover, a content analysis technique became a secondary data collection and it was applied as a way to analyse the response given by the subjects, which was their personal opinion regarding the visual watched.

\section{Result and Discussion}

\section{Emotional differences between Introverts and Extroverts}

The result in Table 1 revealed insignificant differences in emotional changes for Introverts after watching the provocative visual stimuli on Facebook $(Z=-1.170, p=0.077)$; therefore rejecting the $\mathrm{H} 1$. The mean rank value only recorded a slight decrease from 15.93 to 14.65. However, the results were contradicted among the Extroverts. There was a significant difference in emotional changes for Extroverts $(Z=-2.099, p=0.036)$, therefore; $\mathrm{H} 2$ was accepted. The mean rank value decreased significantly from 16.73 to 13.05 , thus showed the exposure to the visual stimuli had an impact on the Extroverts emotions, positively.

In general, the Introverts' emotions remained unchanged after being exposed to the provocative visual stimuli and the same table also indicated that majority of both personalities dealt with stable emotional states after watching the visual stimuli. Not only that, the Extroverts had better emotional control than the Introverts. Overall, the visual has left a positive impact where majority of them are facing emotional stability after watching the stimuli. This situation shows that both personalities feel that the stimuli will influence their inner emotions as well as their action to talk to others. 
TABLE 1: Emotional changes in Introverts and Extroverts, before and after the exposure of provocative visual stimuli $(n=60)$

\begin{tabular}{|c|c|c|c|c|c|c|}
\hline Pair & & & $\mathrm{N}$ & $\begin{array}{l}\text { Mean } \\
\text { Ranks }\end{array}$ & Z & $\begin{array}{l}\text { Sig. } \\
\text { value }\end{array}$ \\
\hline \multirow[t]{4}{*}{ Introverts } & After watching visual - & Negative Ranks & $20^{a}$ & 15.93 & $-1.170^{b}$ & 0.077 \\
\hline & Before watching visual & Positive Ranks & $10^{\mathrm{b}}$ & 14.65 & & \\
\hline & & Ties & $0^{c}$ & & & \\
\hline & & Total & 30 & & & \\
\hline \multirow[t]{4}{*}{ Extroverts } & After watching visual - & Negative Ranks & $20^{a}$ & 16.73 & $-2.099^{b}$ & 0.036 \\
\hline & Before watching visual & Positive Ranks & $10^{b}$ & 13.05 & & \\
\hline & & Ties & $0^{c}$ & & & \\
\hline & & Total & 30 & & & \\
\hline
\end{tabular}

a. Emotional states after < Emotional states before

b. Emotional states after $>$ Emotional states before

c. Emotional states after $=$ Emotional states before

\section{Emotional Responses}

Emotional responses were conveyed into two groups of basic emotions (positive: happy, interest, surprise) and negative (fear, anger, shame, contempt, disgust, guilt, distress), in the form of words or movements (Izard, 1991; Derks et al., 2008; Parkinson, 2008). As stated in Table 2, the emotions would change in one of four forms which are stable-stable, stableunstable, unstable-stable and unstable-unstable. The results found only five Introverts and eleven Extroverts involved in responses sharing thus proving that the Introverts presented interest to participate with the activities but they interacted lesser with the others.

\section{Emotional Responses : Introvert}

Based on one-on-one emotional state analysis, some of the Introverts commented negatively when their emotion was unstable before and after watching the visual. The analysis showed that they used words such as "uninteresting", "unattractive", "boring" and "disgusting":

(Introvert: Emotionally unstable before $\rightarrow$ emotionally unstable after)

"I don't believe in campus politics... The speaker is stuttering and I don't care with whatever he says."

"I didn't even vote... This is not interesting... it's just... so boring. Next?"

"I feel disgusted. They were fighting each other, and then asked me to vote?"

Furthermore, some of the Introverts who faced with stable emotion responded using satire and sarcastic words in longer sentences towards the visual:

(Introvert: Emotionally stable before $\rightarrow$ emotionally stable after)

"Some of the manifestoes cannot be trusted... Very ambitious at first but after that all of you went silent. You always highlight on the popular issues... every year... but the effect is still the same... If you don't know how to do your work ... you are useless." 


\section{Emotional Responses: Extrovert}

Next, an Extrovert with stable emotions would avoid provocation by writing positive comments because they were described as a Sanguine person and wants to be optimist when responding to issues that require opinions:

(Extrovert: Emotionally stable before $\rightarrow$ emotionally stable after) "Sorry to say, they should focus on the study... If they want to be a sweet talker, let them be. It's their life."

"(Sigh) these two three people... fighting... wasting time. It's okay. Just focus on your study..."

"A demonstration won't bring any impact... Please use the right channel..."

The Extroverts who faced emotional instability were convinced with the ability of the speaker to lead, but they felt embarrassed by demonstration and political games thus, illustrate frustration and dissapointment towards the contents:

(Extrovert: Emotionally unstable before $\rightarrow$ emotionally unstable after) "I don't know... What are politics for? Chicken! Chicken... boo!!"

"Students are very up-to-date with current issues but I'm uncomfortable with the protest through demonstrations.

"This is some game by the candidates to win votes... the leader has become a puppet and controlled by the outsider party..."

Shockingly, one of the Extroverts was in a stable emotional state before watching the visual but became unstable after done watching it. Based on the responses, the Extrovert has gone through a bad experience in campus' politics therefore felt offended and frustrated by the issue raised in the visual.

(Extrovert: Emotionally stable before $\rightarrow$ emotionally unstable after) "They are among the fraud... The university calls me a fool, challenge me... They asked many times to re-join the election... I was so fed up with their greed and rotten agenda... Now, I'm too lazy to take part in the corruption happens in the university..."

\section{General Discussion}

In a nutshell, based on the Eysenck Personality Wheel, an emotionally unstable Introvert will have a Melancholic temperament as they shown moody and pessimist character through the disgruntled comments given towards the visual. On the other hand, an emotionally stable Introvert have a cool and quiet temperament but the study found that the Introvert will use satirical words to criticise other people actions or in this context - a political speech. This analysis has given a new character definition for Introvert which is when they are in a stable emotional state, they became a sarcastic person.

The avoidance strategies applied by he Extroverts have made their emotions to be more stable even after watching provocative visuals. The probability of an emotional change from stable to unstable among the Extroverts is seen to stem from the bad experiences faced by the individual who was once involved in the situation thus supporting previous studies stating 
that emotional changes occur due to the environment, relationships and social characters (Sparrevohn \& Rapee 2009; Dezecache, Mercier \& Scott-Phillips 2013; Hammick \& Lee 2014).

TABLE 2: Emotional responses among Introverts and Extroverts

\begin{tabular}{|c|c|c|}
\hline Emotional states & Introverts & Extroverts \\
\hline Stable ${ }^{\mathrm{a}}-$ stable $^{\mathrm{b}}$ & Satire, sarcastic & Avoidance \\
\hline Stable ${ }^{a}-$ Unstable $e^{b}$ & - & Offended, Frustrated \\
\hline Unstable $^{\mathrm{a}}$-stable ${ }^{\mathrm{b}}$ & - & - \\
\hline Unstable $^{\mathrm{a}}$-unstable ${ }^{\mathrm{b}}$ & Pessimistic, moody & $\begin{array}{l}\text { Disappointment, } \\
\text { Embarrassed }\end{array}$ \\
\hline
\end{tabular}

a. Emotional states before

b. Emotional states after

\section{Conclusion}

In conclusion, neutral provocative visual stimuli would change the emotions to be better. Nevertheless, the stability in emotions by Introverts would encourage them to be satirical or cynical. Therefore, satire or cynicism can be summarized as a neutral response strategy because individuals could do it in two ways; either positive or negative. In contrast, Extroverts have a very open and prone towards the environment (in social media or face to face), thus potentially exerted a diverse emotional impact.

The emotional expressions are difficult to interpret in social media because it gives a wider meaning (Laflen \& Fiorenza, 2012) and the content of a message shared by a user will affect one's emotions as well. The pressure from the stimuli can trigger individual's emotions to become stable or unstable (Codispoti et al., 2008). The visual stimuli positively affect the emotional state for both personalities. For example, the Extroverts are more exposed and engaged actively in the discussions and the Introverts projected sarcastic comments even when in a stable emotions.

Taken together, there are three conditions for a successful emotional communication. First, individuals need to provide accurate information, careful in sharing information and develop common interests between users before sharing any information (Dezecache et al., 2013). In parallel with this study, sharing responses among the same audience will influence individuals to form similar meanings towards the topic of the discussion. Therefore, each individual must aware of the unexpected exposure risk disseminated by other social media users; as it will affect the emotions consciously or unconsciously.

\section{References}

Alhabash, S., Baek, J., Cunningham, C., \& Hagerstrom, A. (2015). To comment or not to comment?: How virality, arousal level, and commenting behavior on YouTube videos affect civic behavioral intentions. Computers in Human Behavior, 51, 520-531. https://doi.org/10.1016/j.chb.2015.05.036

Asgari, Y. (2002). Relationship between anxiety and other personality traits among students in a Malaysian university. (Unpublished master dissertation), Universiti Putra Malaysia, Malaysia.

Bazarova, N. N., Taft, J. G., Choi, Y. H., \& Cosley, D. (2012). Managing impressions and relationships on Facebook: Self-presentational and relational concerns revealed 
through the analysis of language style. Journal of Language and Social Psychology, 32(2), 121-141. https://doi.org/10.1177/0261927X12456384

Carlo, G., Mestre, M. V., McGinley, M. M., Samper, P., Tur, A., \& Sandman, D. (2012). The interplay of emotional instability, empathy, and coping on prosocial and aggressive behaviors. Personality and Individual Differences, 53(5), 675-680. https://doi.org/10.1016/j.paid.2012.05.022

Codispoti, M., Surcinelli, P., \& Baldaro, B. (2008). Watching emotional movies: Affective reactions and gender differences. International Journal of Psychophysiology, 69(2), 9095. https://doi.org/10.1016/j. ijpsycho.2008.03.004

Communication \& Multimedia, Pocket Book of Statistics. (2021). Malaysian Communications \& Multimedia Commission, Q4 2020.

Derks, D., Fischer, A. H., \& Bos, A. E. R. (2008). The role of emotion in computer-mediated communication: A review. Computers in Human Behavior, 24(3), 766-785. https://doi.org/10.1016/j. chb.2007.04.004

Dezecache, G., Mercier, H., \& Scott-Phillips, T. C. (2013). An evolutionary approach to emotional communication. Journal of Pragmatics, 59, 221- 233. https://doi.org/10.1016/j.pragma.2013.06.007

Eysenck, H. J., \& Eysenck, S. B. G. (1975). Manual of the Eysenck personality questionnaire (adult). London, England: Hodder \& Stoughton.

Gale, A., Edwards, J., Morris, P., Moore, R., \& Forrester, D. (2001). Extraversion-introversion, neuroticism-stability, and EEG indicators of positive and negative empathic mood. Personality and Individual Differences, 30(3), 449-461. https://doi.org/10.1016/S01918869(00)00036-2

Gallo, D. A., Foster, K. T., \& Johnson, E. L. (2009). Elevated false recollection of emotional pictures in young and older adults. Psychology and Aging, 24(4), 981-988.

Geen, R. G. (1984). Preferred stimulation levels in Introverts and Extraverts: Effects on arousal and performance. Journal of Personality and Social Psychology, 46(6), 1303-1312.

Hammick, J. K., \& Lee, M. J. (2014). Do shy people feel less communication apprehension online? The effects of virtual reality on the relationship between personality characteristics and communication outcomes. Computers in Human Behavior, 33, 302310. https://doi.org/10.1016/j.chb.2013.01.046

Heide, B. V. D., D'Angelo, B., \& Schumaker, E. M. (2012). The Effects of Verbal Versus Photographic Self-Presentation on Impression Formation in Facebook. Journal of Communication, 62(1), 98-116. https://doi.org/10.1111/j.1460-2466.2011.01617.x

Hollenbaugh, E. E., \& Ferris, A. L. (2014). Fa-cebook self-disclosure: Examining the role of traits, social cohesion, and motives. Computers in Human Behavior, 30, 50-58. https://doi.org/10.1016/j.chb.2013.07.055

Huang, A. H., Yen, D. C., \& Zhang, X. (2008). Exploring the potential effects of emoticons. Information \& Management, 45(7), 466-473.

https://doi.org/10.1016/j.im.2008.07.001

Izard, C. E. (1991). Interest-Excitement: Activation, Expression, and Experience. The Psychology of Emotions, 89-108. https://doi.org/10.1007/978-1-4899-0615-1_4

Kadri, N. H. M., Omar, S. Z., Abdullah, R., \& Adzharuddin, N. A. (2019). Words of 'keyboard warriors': Comparing the use of harsh language in two Facebook pages. Human Communication, 2(2), 25-41. 
Krämer, N. C., Feurstein, M., Kluck, J. P., Meier, Y., Rother, M., \& Winter, S. (2017). Beware of selfies: The impact of photo type on impression formation based on social networking profiles. Frontiers in Psychology, 8, 1-14. https://doi.org/10.3389/fpsyg.2017.00188

Laflen, A., \& Fiorenza, B. (2012). "Okay, my rant is over." The language of emotion in computer-mediated communication. Computers and Composition, 29(4), 296-308. https://doi.org/10.1016/j.compcom.2012.09.005

Ljepava, N., Orr, R. R., Locke, S., \& Ross, C. (2013). Personality and social characteristics of Facebook non-users and frequent users. Computers in Human Behavior, 29(4), 16021607. https://doi.org/10.1016/j.chb.2013.01.026

Mack, D. M., Behler, A., Roberts, B., \& Rimland, E. (2007). Reaching students with Facebook: Data and best practices. Electronic Journal of Academic and Special Librarianship, 8(2). Retrieved January 11, 2014, from http:// southernlibrarianship.icaap.org/content/v08n02/ mack_d01.html

Mitchell, M. E., Lebow, J. R., Uribe, R., Grathouse, H., \& Shoger, W. (2011). Internet use, happiness, social support and introversion: A more fine grained analysis of person variables and internet activity. Computers in Human Behavior, 27(5), 1857-1861. https://doi.org/10.1016/j.chb.2011.04.008

Moore, K., \& McElroy, J. C. (2012). The influence of personality on Facebook usage, wall postings, and regret. Computers in Human Behavior, 28(1), 267-274. https://doi.org/10.1016/j.chb.2011.09.009

Okdie, B. M., Guadagno, R. E., Bernieri, F. J., Geers, A. L., \& Mclarney-Vesotski, A. R. (2011). Getting to know you: Face-to-face versus online interactions. Computers in Human Behavior, 27(1), 153-159. https://doi.org/10.1016/j.chb.2010.07.017

Orchard, L. J., Fullwood, C., Galbraith, N., \& Morris, N. (2014). Individual differences as predictors of social networking. Journal of Computer-Mediated Communication, 19(3), 1-15. https://doi.org/10.1111/jcc4.12068

Parkinson, B. (2008). Emotions in direct and remote social interaction: Getting through the spaces between us. Computers in Human Behavior, 24(4), 1510-1529. https://doi.org/10.1016/j. chb.2007.05.006

Powers, S. R., Rauh, C., Henning, R. A., Buck, R. W., \& West, T. V. (2011). The effect of video feedback delay on frustration and emotion communication accuracy. Computers in Human Behavior, 27(5), 1651-1657. https://doi.org/10.1016/j. chb.2011.02.003

Qiu, L., Lin, H., Ramsay, J., \& Yang, F. (2012). You are what you tweet: Personality expression and perception on Twitter. Journal of Research in Personality, 46(6), 710-718. https://doi.org/10.1016/j.jrp.2012.08.008

Rafnsdottir, H. B. (2012). Are Emotional Video-Clips More Likely to Elicit False Memories Than Neutral Video-Clips? (Unpublished degree dissertation). Reykjavík University.

Rooney, B., Benson, C., \& Hennessy, E. (2012). The apparent reality of movies and emotional arousal: A study using physiological and self-report measures. Poetics, 40(5), 405-422. https://doi.org/10.1016/j. poetic.2012.07.004

Reips, U. (2002). Standards for Internet-Based Experimenting. Experimental Psychology, 49(4), 243-256. https://doi.org/10.1026/1618-3169.49.4.243

Sani, F., \& Todman, J. B. (2006). Experimental design and statistics for psychology: A first course. Malden, USA: Blackwell Pub. 
Sparrevohn, R. M., \& Rapee, R. M. (2009). Self-disclosure, emotional expression and intimacy within romantic relationships of people with social phobia. Behaviour Research and Therapy, 47(12), 1074-8. https://doi.org/10.1016/j.brat.2009.07.016

Srivastava, S., Angelo, K. M., \& Vallereux, S. R. (2008). Extraversion and positive affect: A day reconstruction study of person-environment transactions. Journal of Research in Personality, 42(6), 1613-1618. https://doi.org/10.1016/j.jrp.2008.05.002

Stemmler, G., \& Wacker, J. (2010). Personality, emotion, and individual differences in physiological responses. Biological Psychology, 84(3), 5415-51. https://doi.org/10.1016/j.biopsycho.2009.09.012

Tosun, L. P., \& Lajunen, T. (2010). Does Internet use reflect your personality? Relationship between Eysenck's personality dimensions and Internet use. Computers in Human Behavior, 26(2), 162-167. https://doi.org/10.1016/j.chb.2009.10.010

Walther, J. B. (1996). Computer-mediated communication: Impersonal, interpersonal, and hyperpersonal interaction. Communication Research, 23(1), 3-43. https://doi.org/10.1177/009365096023001001

Walther, J. B. (2007). Selective self-presentation in computer-mediated communication: Hyperpersonal dimensions of technology, language, and cognition. Computers in Human Behavior, 23(5), 2538-2557. https://doi.org/10.1016/j.chb.2006.05.002

Wang, J. L., Jackson, L. A., Zhang, D. J., \& Su, Z. Q. (2012). The relationships among the Big Five Personality factors, self-esteem, narcissism, and sensation-seeking to Chinese university students' uses of social networking sites (SNSs). Computers in Human Behavior, 28(6), 2313- 2319. https://doi.org/10.1016/j.chb.2012.07.001

Wilson, K., Fornasier, S. \& White, K. M. (2010). Psychological predictors of young adults' use of social networking sites. Cyberpsychology, Behavior, and Social Networking, 13(2), 173-177. https://doi.org/10.1089/cyber.2009.0094

Winter, S., Neubaum, G., Eimler, S. C., Gordon, V., Theil, J., Herrmann, J., \& Kramer, N. C. (2014). Another brick in the Facebook wall - How personality traits relate to the content of status updates. Computers in Human Behavior, 34, 194-202. https://doi.org/10.1016/j.chb.2014.01.048 